\title{
Female Guinea Pig Model for Cough Studies and Its Response to Most Common Tussive Substances
}

\author{
Miroslav STERUSKY ${ }^{1}$, Jana PLEVKOVA ${ }^{1}$, Marian GRENDAR ${ }^{2}$, Tomas BUDAY ${ }^{1}$ \\ ${ }^{1}$ Department of Pathophysiology, Jessenius Faculty of Medicine, Comenius University in \\ Bratislava, Martin, Slovak Republic, ${ }^{2}$ Biomedical Centre Martin, Jessenius Faculty of Medicine, \\ Comenius University in Bratislava, Martin, Slovak Republic
}

Received September 23, 2019

Accepted November 20, 2019

\begin{abstract}
Summary
Laboratory research of cough reflex utilizes almost exclusively male guinea pigs - a practice that represents a significant obstacle in the successful translation of results into clinical practice. Chronic hypersensitivity cough syndrome affects mostly postmenopausal women and it represents significant decrease in patient's quality of life. No cause for such exaggerated cough can be found, therefore this condition cannot be treated appropriately. One of the reasons leading to the lack of relevant data about mechanisms responsible for hypersensitivity of cough related pathways is nowadays widely discussed gender bias, which is present in nearly all branches of biomedical research. Since gender differences in cough reflex physiology do exist in humans, it would be reasonable to study cough-related phenomena on both sexes of laboratory animals. In this study, we focused on detailed characterization of cough response of female guinea pigs to aerosols of commonly used tussive agents (capsaicin, distilled water, allyl isothiocyanate, cinnamaldehyde, citric acid). In pooled data from multiple challenges we found no statistical difference in number of cough and cough latency between sexes. Based on our results we conclude that the utilization of female guinea pigs model does not lead to messy data and can be used in basic cough research.
\end{abstract}

\section{Key words}

Gender bias $\bullet$ Chronic cough $\bullet$ Guinea pigs $\bullet$ Female model

\section{Corresponding author}

Tomas Buday, Department of Pathophysiology, Jessenius Faculty of Medicine in Martin, Comenius University in Bratislava, Mala Hora 4C, 03601 Martin, Slovak Republic. Email: tomas.buday@uniba.sk

\section{Introduction}

Cough is the most important airway defensive reflex as long as it serves its physiological function (Korpas and Tomori 1979). Up-regulation of cough response by pathological processes affecting the peripheral or central cough related neural pathways usually leads to excessive coughing, which does not meet a definition of protecting reflex, but rather becomes troublesome and reduces the quality of life (Morice 2013, Escamilla and Roche 2014).

Cough hypersensitivity syndrome - one of the clinical entities characterized by "up-regulation" of cough related neuronal circuits affects predominantly postmenopausal women, contributing to more than $2 / 3$ of patients visiting specialized cough clinical worldwide (Morice et al. 2014, Song et al. 2015). Moreover, there are studies which have clearly confirmed gender differences in cough in humans (Roorda et al. 1993, Kastelik et al. 2002, Demoulin-Alexikova et al. 2016). Several causes of these gender differences are to be implied, but the effect of sex hormones and their decrease represents the most favoured cause. Varechova et al. have confirmed that the changes in cough sensitivity between boys and girls occur in puberty (Varechova et al. 2008), which supports the theory of hormonal influence and other work from our department also documents that cough response of young fertile women depends on their hormonal status (Kavalcikova-Bogdanova et al. 2018). However, the underlying condition responsible for hypersensitive cough reflex in postmenopausal women - which would be the key to successful treatment - remains unidentified. 
The substantial reason for the lack of relevant scientific information about hypersensitive cough in postmenopausal women is the gender bias that has existed in respiratory research for decades, without evidence that would justify the exclusion of female subjects from cough research (Beery and Zucker 2011). The neglect of female from the research is rooted in the erroneous belief that circulating ovarian hormones make the data from female animals messier and more variable than data from males, which was not confirmed by detailed analysis of variability of multiple physiological, cellular and other parameters (Shansky 2019). Even higher variability exists in the data obtained from male rodents caged in groups of three or more, where subjects have different levels of testosterone and stress hormones depending on their social status in the cage - dominant male versus subordinates (Shansky 2019).

Validated female-only animal model or model utilizing both sexes of animals would definitely contribute to the improvement of knowledge about hypersensitive cough in women. Therefore, the aim of presented study is to characterize cough response of female Dunkin-Hartley guinea pigs to wide variety of tussigens - citric acid, capsaicin, distilled water, cinnamaldehyde and allyl isothiocyanate and to compare basic parameters of cough response to those obtained in male guinea pigs in order to determine its reproducibility and stability over time and repeated measurements.

\section{Material and methods}

\section{Ethical approval}

The study was approved by the Ethical Committee of Jessenius Faculty of Medicine in Martin, Comenius University in Bratislava under protocol no. $1917 / 2017$.

\section{Study design}

The study was conducted throughout 2017 - 2019 on male and female Dunkin-Hartley guinea pigs (males in total: $n=40$, age 7 weeks at the time of first measurement, females in total: $n=38$, age 7 weeks at the time of first measurement), obtained from an accredited breeding facilities (Innovo Kft., Hungary, Central Animal Housing, Jessenius Faculty of Medicine in Martin). The animals were housed in an approved animal holding facility maintained at a controlled room temperature of $21-22{ }^{\circ} \mathrm{C}$, with humidity 50-60\%, ventilation, a 12-h light-dark cycle, and with free access to water and standard animal food.
Animal care was provided, and the experiments were conducted in agreement with the Animal Welfare Guidelines of the Comenius University and the statutes and rules of the Slovak Republic (protocol no 3467/13221).

Adaptation of animals to laboratory conditions was performed in two phases. The animals were in contact with laboratory personnel daily prior to experimental measurements, during which they were exposed to laboratory conditions for approximately two hours twice. During this adaptation period, they were also placed inside a plethysmographic box and inhaled an aerosol of saline for 2 min to familiarize with the procedure of inhalation itself. Every day prior to challenge, they spent at least $30 \mathrm{~min}$ in the laboratory to adapt to laboratory conditions and reduce the stress from transport from the animal housing facility.

\section{Cough challenges in conscious guinea pigs}

The conscious animals were individually placed in the plethysmograph (type 855, Hugo Sachs Electronic, March, Germany) which consisted of a head and a body chamber. The opening between the head and body chambers was equipped with a plastic collar lining around the animal's neck to prevent communication between chambers. An appropriate collar size was chosen for each animal to prevent neck compression. The head chamber was connected to a nebulizer (Pari Provokation Test I, Menzel, Germany, manufacturer's specification: output $51 \mathrm{~min}^{-1}$, particle mass median aerodynamic diameter $1.2 \mu \mathrm{m})$. A suction device adjusted to the same input flow $\left(51 \mathrm{~min}^{-1}\right)$ was connected to the head chamber to maintain constant airflow through the chamber during the aerosol administration. Airflow changes were measured using a pneumotachograph (Godart, Germany) with a Fleisch head connected to the head chamber. These data were recorded with the acquisition system ACQ Knowledge (Biopack, Santa Barbara, CA, USA). Respiratory sounds were recorded with a microphone placed in the roof of the head chamber and connected to a preamplifier and MP3 recorder. The pneumotachographical and microphone output were simultaneously recorded for the off-line analysis.

The cough was defined as an expiratory airflow interrupting the basic respiratory pattern accompanied by a coughing sound. Coughs were analyzed (using coughrelated sounds and airflow) by two trained persons who were blind to the gender of animals. The most important task of the observers was to differentiate coughs from 
sneezes and artefacts by the software Sonic Visualizer. Their results were compared and (if no statistically significant differences occurred) averaged.

Cough challenges were performed using inhalation of $0.4 \mathrm{M}$ citric acid, $50 \mu \mathrm{M}$ capsaicin, distilled water, $10 \mathrm{mM}$ allyl isothiocyanate and $10 \mathrm{mM}$ cinnamaldehyde for $5 \mathrm{~min}$ without any pre-treatment.
Cough challenges were performed at least a week apart in order to prevent tachyphylaxis.

\section{Chemicals}

Capsaicin, citric acid, allyl isothiocyanate and cinnamaldehyde were purchased from Sigma-Aldrich (St. Louis, MO, USA).
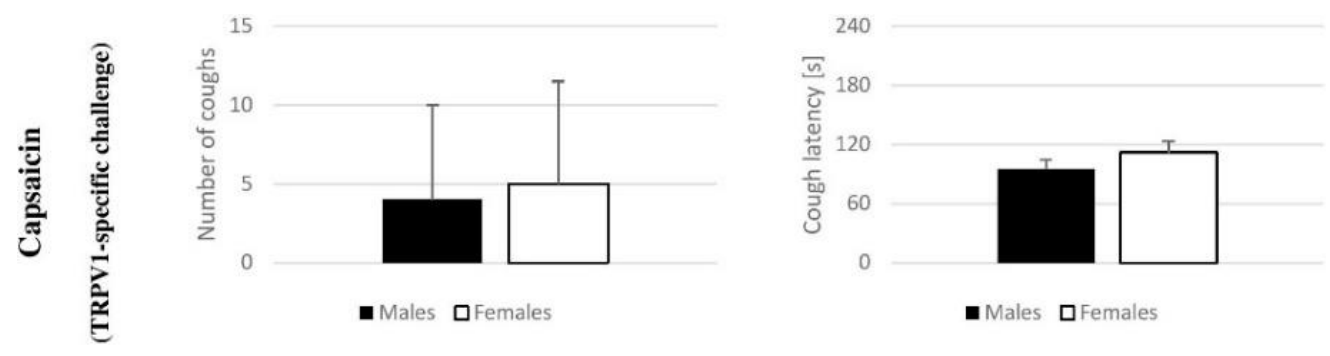

Fig. 1. Pooled data for number of coughs (left column) and cough latency (right column) obtained in different cough challenges
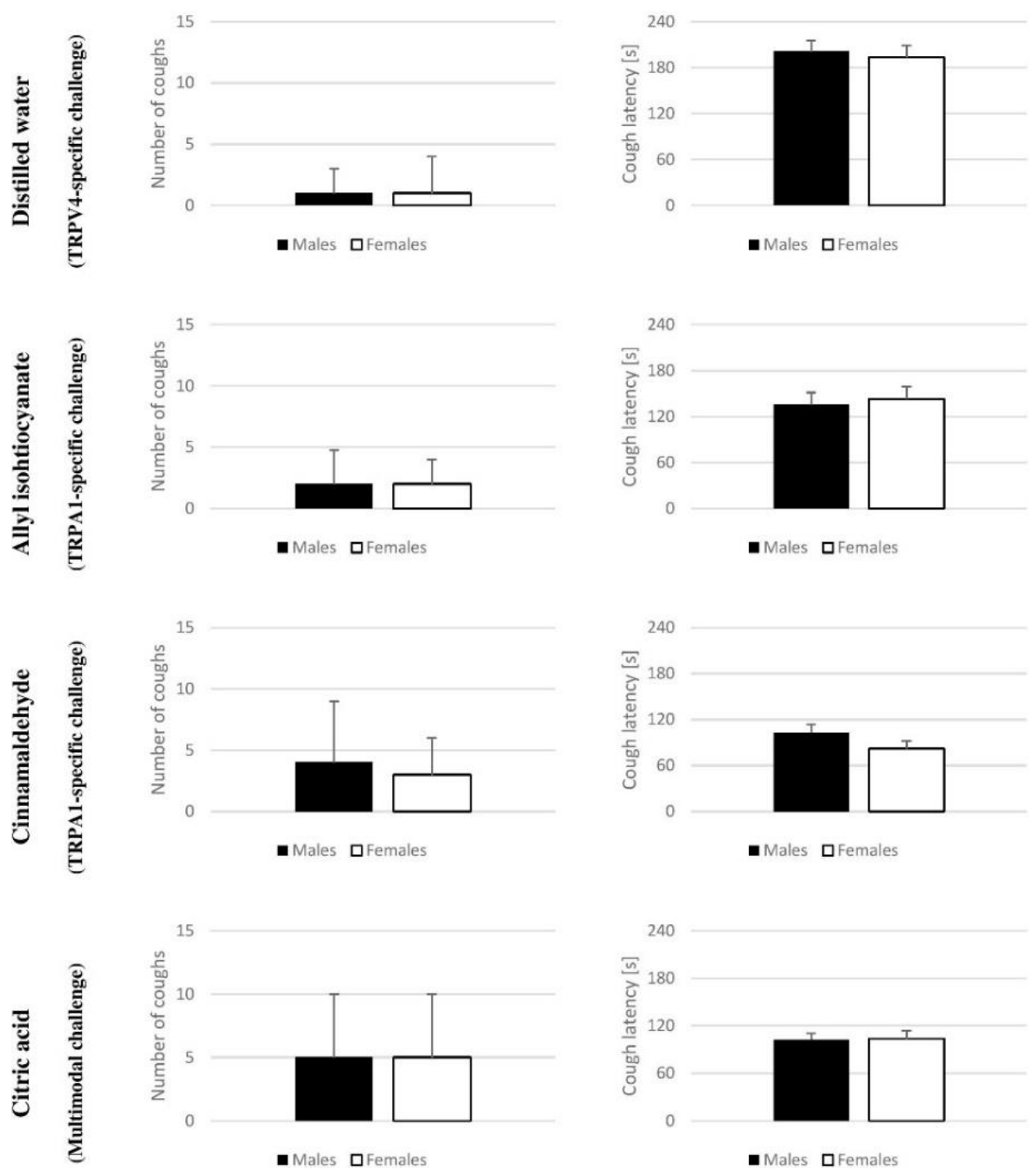


\section{Statistical analysis}

Data were summarized by the standard summary statistics and visualized by boxplot overlaid with swarm plot. Normality of data in subgroups was assessed by the quantile-quantile plot (QQplot) with the $95 \%$ confidence band, constructed by bootstrap.

The QQplot served also for visual identification of the outlying observations. The repeated measures ANOVA model was estimated using the linear mixed model, with the outliers excluded. Multiple comparisons posthoc analyses were performed with the Benjamini Hochberg adjustment of p-values.

The data were analyzed using $\mathrm{R}$ ( $\mathrm{R}$ Core Team, 2018) ver. 3.5.2, with the aid of the libraries nlme (Pinheiro et al. 2018) and multcomp (Hothorn et al. 2008). $P<0.05$ was considered statistically significant.

The data for the final cough count is expressed as median \pm interquartile range. The data for cough latency is expressed as the average \pm standard error of the mean. Graphs were plotted in Microsoft Excel.

\section{Results}

\section{Pooled data}

In general, in repeated challenges with given tussive agents we did not find significant differences between sexes of animals - that would lead to "messy" data or samples with obviously high variability.

In capsaicin challenge, the number of coughs (males vs. females) was $4 \pm 6$ vs. $5 \pm 6.5$ and the cough latency was $94.7 \pm 9.96 \mathrm{~s}$ vs $112.0 \pm 11.43 \mathrm{~s}$. In distilled water challenge, the number of coughs was $1 \pm 2$ vs. $1 \pm 3$ and the cough latency was $200.9 \pm 14.61 \mathrm{~s}$ vs. $193.6 \pm 15.58$ s. In allyl isothiocyanate challenge, the number of observed coughs was $2 \pm 2.75$ vs. $2 \pm 2$ and the observed cough latency was $135.4 \pm 16.03$ s vs. $142.9 \pm 16.34$ s. In cinnamaldehyde challenge, the number of coughs was $4 \pm 3$ vs. $5 \pm 3$ and cough latency was $103.0 \pm 10.38 \mathrm{~s}$ vs. $82.0 \pm 9.72$ and finally, in citric acid cough challenge, the number of observed coughs was $5 \pm 5$ vs. $5 \pm 5$ and cough latency was $102.5 \pm 8.04 \mathrm{~s}$ vs. $103.6 \pm 9.64 \mathrm{~s}$ (Fig. 1).

\section{Capsaicin challenge in detail}

Capsaicin activates TRPV1 (transient receptor potential channel, member V1) channel present on vagal C fibers and it is one of the most commonly used tussive agents in cough research both in the laboratory and in clinical settings. Moreover, C-fibers are presumably related to the regulatory role of oestrogen, in which $75 \%$ of C-fibers associated neurons that express TRPV1 also express oestrogen receptor $\alpha$ (Peng et al. 2008), so we offer a more detailed analysis of capsaicin-induced cough. But still, the results obtained from all other tested tussive agents followed the same pattern - no differences between male and female groups in repeated measurements.

The number of coughs obtained in capsaicin challenges ranged from $1.5 \pm 2$ to $10 \pm 8.5$ coughs in males and from $1 \pm 1$ to $11 \pm 2.25$ in female guinea pigs. Summarized results are shown in Fig. 2.

The latency of cough obtained in capsaicin challenges ranged from $35.5 \pm 5.89$ to $178 \pm 35.03$ seconds in males and from $36.5 \pm 8.28$ to $234.2 \pm 26.71$ seconds in female guinea pigs. Summarized results are shown in Fig. 3.
Fig. 2. Results of capsaicin cough challenge - number of coughs. Measurements from 2017 were obtained during spring, whereas the remaining measurements were obtained during autumn - seasonal variability of cough research is well-known among cough researchers (Korpas and Tomori 1979) and yet the number of coughs still does not display gender differences. 


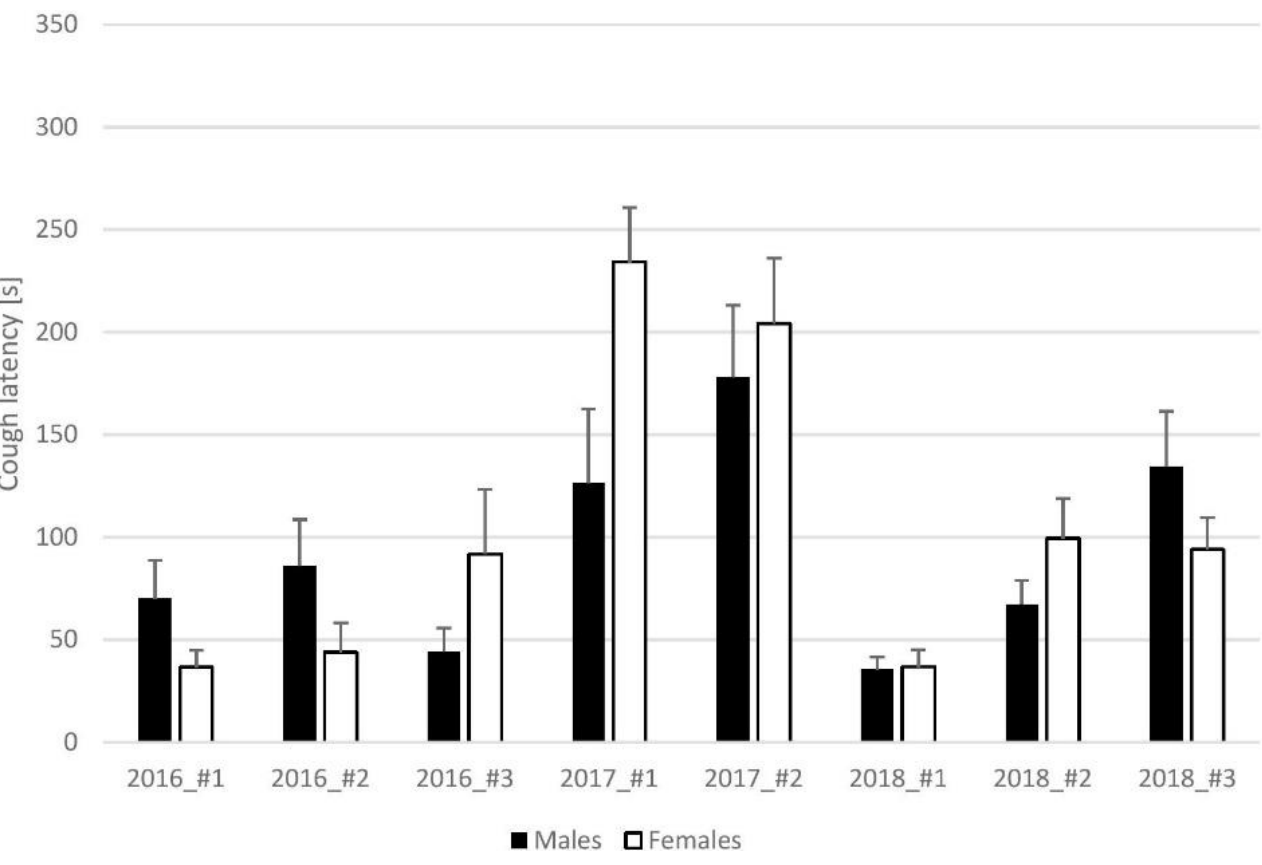

Fig. 3. Results of capsaicin cough challenges - cough latency. Measurements from 2017 were obtained during spring, whereas the remaining measurements were obtained during autumn - seasonal variability of cough research is well-known among cough researchers (Korpas and Tomori 1979) and yet the cough latency still does not display gender differences.

\section{Discussion}

The most important result of our study is that female guinea pigs respond the same way to the most common tussive substances as male guinea pigs, irrespective to the hormonal status of the animal. To our best knowledge, this study is the first study describing the cough response of female guinea pigs to more tussive substances in the sets of repeated challenges. It is continuation of our pilot study analyzing cough response to citric acid in couple of animals $(n=8)$, which showed no obvious differences in cough count and cough latency with higher variability in both parameters (Plevkova et al. 2016).

Since the cough can be provoked by multitude of chemical stimuli depending on the type of the receptor expressed on sensory vagal airway nerves - mainly $\mathrm{C}$ fibers (expressing e.g. TRPV1, TRPA1, TRPV4) (Belvisi 2003, Canning 2008, Belvisi et al. 2013), we looked in detail to most tussive substances used commonly in experimental cough research. Therefore, the present study assessed cough response to citric acid, capsaicin (Pecova et al. 2007), cinnamaldehyde, allyl isothiocyanate (Brozmanova et al. 2012, Brozmanova et al. 2013) and distilled water as well. We utilized cough challenges which provoke cough by activation of different ion channels on airway C-fiber nerve terminals and none of these (TRPV1, TRPA1, TRPV4, ASIC) revealed any statistically significant gender differences. In addition, we did not observe the increased variability in females seen in our previous study. This is very likely due to a high number of animals which made the data more homogenous.

Male laboratory animals are used exclusively as a model in experimental cough research for decades (Belvisi and Bolser 2002). Closer investigation why such methodology is set did not find an answer on why female guinea pigs are excluded. Using appropriate keywords to search in international databases we found only three studies mentioning the utilization of female guinea pigs in basic cough research. The first one is the study of Forsberg et al. from 1988, as one of the earliest cough studies in conscious guinea pigs, which utilized animals of both sexes, however, the sex of experimental animal was not taken into account in the analysis of results (Forsberg et al. 1988). The second study which utilized both sexes investigated the role of antioestrogen drug danazol on cough evoked by ACE inhibitor administration (Ebihara et al. 1996). The last study we found was a study by Japanese authors who tested the effect of azelastine (Ito et al. 2002). The study utilized only female guinea pigs, however the authors do not provide the reason behind choosing female guinea pigs for experiments.

Such misrepresentation of one sex studies in biomedical research has been termed "gender bias", as a great majority of experiments performed on one gender unambiguously prefer males - not only in cough research but throughout biomedical research. The ratio of scientific publications with experiments conducted on males versus experiments conducted on females is most skewed in fields of neuroscience $(5.5: 1)$, pharmacology 
and physiology (3,7:1) (Beery and Zucker 2011) - all these fields are highly relevant for study of up-regulated cough reflex. The non-existence of gender differences out of the reproductive system cannot be just assumed or neglected (Arnold 2009).

It was clearly confirmed that sensitivity to inhaled capsaicin in men and women is different both in healthy individuals as well as subjects with chronic cough (Dicpinigaitis and Rauf 1998, Kastelik et al. 2002). Since gender differences in human cough do exist, there is a question why we did not detect any in our model, which is considered to be the most suitable model for cough research (Belvisi and Bolser, 2002). Neurophysiology of guinea pig vagus nerve is the closest one to that of humans - it depolarizes in the same manner (Belvisi and Bolser, 2002). If we consider that based on extensive studies peripheral sensory pathways of cough in humans and guinea are very similar, there must be difference in the central neural circuits regulating cough, which can be presumably responsible for the gender dimorphism. Similar data were published in a pain study, where gender differences were detected. Responses of nociceptors were not significantly different, however threshold for nociceptive behavior was different in female. These differences are supposed to be caused by sexual dimorphism in central nervous system (Hendrich $e t$ al. 2012).

Recently, attention in cough research is given to the supramedullary circuits modulating cough, e.g. urgeto-cough sensation or descending inhibitory system etc. (Mazzone et al. 2013). Gender differences were detected by fMRI scans in women and men after single-dose capsaicin inhalation that has provoked cough (Morice et al. 2014), therefore we can speculate that very likely higher brain circuits are responsible for observed gender differences in humans. Even though such imaging techniques can be used in animals, they have never been performed. Participation of supramedullary influences on cough in animals was confirmed - e.g. anaesthetized guinea pigs do not cough to chemical stimuli (Canning and Mori 2011, Chen et al. 2017) therefore it is clear that supramedullary parts of the guinea pig brain are necessary to initiate cough motor pattern after exposure to chemicals (Canning and Mori 2011, Ji et al. 2018). However, it is unclear to what extent they differ between sexes.

Regarding the gender dimorphism in cough sensitivity, the question of airway afferents is frequently discussed. To our best knowledge there is no available data about sex differences in structure or function of airway afferent nerves nor the differences in expression of ion channels or other sensors/transducers relevant for cough reflex. Even in similar expression pattern between sexes, these channels, sensors and transducers can be modulated in a different way in the presence of sex hormones (ArteroMorales et al. 2018).

Today, only a limited explanation of possible gender difference in cough sensitivity in humans can be provided - and this insight comes from pain research. Cough and pain neural mechanisms are very similar - both of them are mediated by $\mathrm{C}$ and $\mathrm{A} \delta$ sensory fibers analyzed and processed by supramedullary neuronal circuits with holoarchial architecture (Bolser et al. 2006) and modulated by the activity of cerebral cortex (Mazzone et al. 2013).

Several mechanisms of estrogen and progesterone interaction with C-fiber pathways are known. Estrogen enhances nociception indirectly via the release of prolactin which as neuromodulator increases phosphorylation of the nociceptor transducer TRPV1. The so-called non-classical estrogen-signalling pathway was recently recognized as well, which affects capsaicin binding site and this limits nociception (Vodo et al. 2013). Progesterone, the concentration of which increases in the luteal phase of the cycle in women is known to modulate effects of estrogen on afferents (Kuba et al. 2006). These findings are consistent with clinical reports that female pelvic pain increases after reduction of circulating estrogens (Vodo et al. 2013). Female cough also gets worse after estrogen withdrawal (e.g. in menopause) estrogen seems to stabilize the afferent nociceptive drive, and this effect is reversed by progesterone (Vodo et al. 2013).

Many studies published in recent years prove that study of males and females (therefore, mostly females from this point of view) provides reproducible results even without tracking of hormonal cycles (Goy et al. 1980), as the gender differences are - in any case - incompletely explained by actions of sex hormones (Cahill 2006, Arnold, 2009). We assume that it is necessary to use both sexes of animals in experimental cough research. This female model will be tested in experimental airway inflammation (Brozmanová et al. 2006), to assess how it responds to pathological processes affecting the airways. We suppose that it will not produce messy data, and it will be more suitable model with higher translational potential to the population of affected individuals which are in this case mainly women.

\section{Conflict of Interest}

There is no conflict of interest. 


\section{Acknowledgements}

\section{References}

ARNOLD AP: The organizational-activational hypothesis as the foundation for a unified theory of sexual differentiation of all mammalian tissues. Horm Behav 55: 570-578, 2009. https://doi.org/10.1016/j.yhbeh.2009.03.011

ARTERO-MORALES M, GONZÁLEZ-RODRÍGUEZ S, FERRER-MONTIEL A: TRP channels as potential targets for sex-related differences in migraine pain. Front Mol Biosci 5: 73, 2018. https://doi.org/10.3389/fmolb.2018.00073

BEERY AK, ZUCKER I: Sex bias in neuroscience and biomedical research. Neurosci Biobehav Rev 35: 565-572, 2011. https://doi.org/10.1016/j.neubiorev.2010.07.002

BELVISI MG: Sensory nerves and airway inflammation: role of A delta and C-fibers. Pulm Pharmacol Ther 16: 1-7, 2003. https://doi.org/10.1016/S1094-5539(02)00180-3

BELVISI MG, BOLSER DC: Summary: animal models for cough. Pulm Pharmacol Ther 15: 249-250, 2002. https://doi.org/10.1006/pupt.2002.0349

BELVISI MG, BONVINI SJ, GRACE MS, CHING Y-M, DUBUIS E, ADCOCK JJ, BIRRELL MA: Activation of airway sensory nerves: a key role for the TRPV4 channel. In: D19. What's Going on? Mechanisms of Remodeling and Hyperresponsiveness, American Thoracic Society International Conference Abstracts. American Thoracic Society, 2013, p. A5265.

BOLSER DC, POLIACEK I, JAKUS J, FULLER DD, DAVENPORT PW: Neurogenesis of cough, other airway defensive behaviors and breathing: A holarchical system? Respir Physiol Neurobiol 152: 255-265, 2006. https://doi.org/10.1016/j.resp.2006.01.008

BROZMANOVA M, CALKOVSKY V, PLEVKOVA J, BARTOS V, PLANK L, TATAR M: Early and late allergic phase related cough response in sensitized guinea pigs with experimental allergic rhinitis. Physiol Res 55: $577-$ 584, 2006.

BROZMANOVA M, MAZUROVA L, RU F, TATAR M, KOLLARIK M: Comparison of TRPA1-versus TRPV1mediated cough in guinea pigs. Eur J Pharmacol 689: 211-218, 2012. https://doi.org/10.1016/j.ejphar.2012.05.048

BROZMANOVA M, MAZUROVA L, TATAR M, KOLLARIK M: Evaluation of the effect of GABA(B) agonists on the vagal nodose C-fibers in the esophagus. Physiol Res 62: 285-295, 2013.

CAHILL L: Why sex matters for neuroscience. Nat Rev Neurosci 7: 477-484, 2006. https://doi.org/10.1038/nrn1909

CANNING BJ: The cough reflex in animals: relevance to human cough research. Lung 186 (Suppl 1): S23-S28, 2008. https://doi.org/10.1007/s00408-007-9054-6

CANNING BJ, MORI N: Encoding of the cough reflex in anesthetized guinea pigs. Am J Physiol Regul Integr Comp Physiol 300: R369-R377, 2011. https://doi.org/10.1152/ajpregu.00044.2010

CHEN Z, CHEN H, CHEN F, GU D, SUN L, ZHANG W, FAN L, LIN Y, DONG R, LAI K: Vagotomy decreases the neuronal activities of medulla oblongata and alleviates neurogenic inflammation of airways induced by repeated intra-esophageal instillation of $\mathrm{HCl}$ in guinea pigs. Physiol Res 66: 1021-1028, 2017. https://doi.org/10.33549/physiolres.933574

DEMOULIN-ALEXIKOVA S, PLEVKOVA J, MAZUROVA L, ZATKO T, ALEXIK M, HANACEK J, TATAR M: Impact of air pollution on age and gender related increase in cough reflex sensitivity of healthy children in Slovakia. Front Physiol: 7: 54, 2016. https://doi.org/10.3389/fphys.2016.00054

DICPINIGAITIS PV, RAUF K: The influence of gender on cough reflex sensitivity. Chest 113: 1319-1321, 1998. https://doi.org/10.1378/chest.113.5.1319

EBIHARA T, SEKIZAWA K, OHRUI T, NAKAZAWA H, SASAKI H: Angiotensin-converting enzyme inhibitor and danazol increase sensitivity of cough reflex in female guinea pigs. Am J Respir Crit Care Med 153: 812-819, 1996. https://doi.org/10.1164/ajrccm.153.2.8564137

ESCAMILLA R, ROCHE N: Cough hypersensitivity syndrome: towards a new approach to chronic cough. Eur Respir J 44: 1103-1106, 2014. https://doi.org/10.1183/09031936.00150614 
FORSBERG K, KARLSSON JA, THEODORSSON E, LUNDBERG JM, PERSSON CG: Cough and bronchoconstriction mediated by capsaicin-sensitive sensory neurons in the guinea-pig. Pulm Pharmacol 1: 3339, 1988. https://doi.org/10.1016/0952-0600(88)90008-7

GOY RW, MCEWEN BS and Neurosciences Research Program: Sexual differentiation of the brain: based on a work session of the Neurosciences Research Program. MIT Press, Cambridge, Mass, 1980.

HENDRICH J, ALVAREZ P, JOSEPH EK, FERRARI LF, CHEN X, LEVINE JD: In vivo and in vitro comparison of female and male nociceptors. J Pain 13: 1224-1231, 2012. https://doi.org/10.1016/j.jpain.2012.09.009

HOTHORN T, BRETZ F, WESTFALL P: Simultaneous inference in general parametric models. Biom J 50: 346-363, 2008. https://doi.org/10.1002/bimj.200810425

ITO N, SHIOYA T, WATANABE A, SANO M, SASAKI M, MIURA M: Mechanism of the antitussive effect of azelastine in guinea pigs. Arzneimittelforschung 52: 441-447, 2002. https://doi.org/10.1055/s-0031-1299912

JI Z, WANG Z, CHEN Z, JIN H, CHEN C, CHAI S, LV H, YANG L, HU Y, DONG R, LAI K: Melatonin attenuates chronic cough mediated by oxidative stress via transient receptor potential melastatin-2 in guinea pigs exposed to particulate matter 2.5. Physiol Res 67: 293-305, 2018. https://doi.org/10.33549/physiolres.933654

KASTELIK JA, THOMPSON RH, AZIZI, OJOO JC, REDINGTON AE, MORICE AH: Sex-related differences in cough reflex sensitivity in patients with chronic cough. Am J Respir Crit Care Med 166: 961-964, 2002. https://doi.org/10.1164/rccm.2109061

KAVALCIKOVA-BOGDANOVA N, KOVACIKOVA L, BUDAY T, BIRINGER K, SIVAKOVA J, CALKOVSKY V, ANTOSOVA M, PLEVKOVA J: Sensitivity of airway cough-related afferents is influenced by female sex hormones. Respir Physiol Neurobiol 257: 12-17, 2018. https://doi.org/10.1016/j.resp.2018.01.006

KORPAS J, TOMORI Z: Cough and Other Respiratory Reflexes. Karger, Basel, 1979.

KUBA T, WU H-BK, NAZARIAN A, FESTA ED, BARR GA, JENAB S, INTURRISI CE, QUINONES-JENAB V: Estradiol and progesterone differentially regulate formalin-induced nociception in ovariectomized female rats. Horm Behav 49: 441-449, 2006. https://doi.org/10.1016/j.yhbeh.2005.09.007

MAZZONE SB, MCGOVERN AE, YANG S-K, WOO A, PHIPPS S, ANDO A, LEECH J, FARRELL MJ: Sensorimotor circuitry involved in the higher brain control of coughing. Cough 9: 7, 2013. https://doi.org/10.1186/1745-99749-7

MORICE AH: Chronic cough hypersensitivity syndrome. Cough 9: 14, 2013. https://doi.org/10.1186/1745-9974-9-14

MORICE AH, JAKES AD, FARUQI S, BIRRING SS, MCGARVEY L, CANNING B, SMITH JA, PARKER SM, CHUNG KF, LAI K, PAVORD ID, VAN DEN BERG J, SONG W-J, MILLQVIST E, FARRELL MJ, MAZZONE SB, DICPINIGAITIS P, CHRONIC COUGH REGISTRY: A worldwide survey of chronic cough: a manifestation of enhanced somatosensory response. Eur Respir J 44: 1149-1155, 2014. https://doi.org/10.1183/09031936.00217813

PECOVA R, JAVORKOVA N, KUDLICKA J, TATAR M: Tussigenic agents in the measurement of cough reflex sensitivity. J Physiol Pharmacol 58 (Suppl 5): 531-538, 2007.

PENG H-Y, HUANG P-C, LIAO J-M, TUNG K-C, LEE S-D, CHENG C-L, SHYU J-C, LAI C-Y, CHEN G-D, LIN TB: Estrous cycle variation of TRPV1-mediated cross-organ sensitization between uterus and NMDA-dependent pelvic-urethra reflex activity. Am J Physiol Endocrinol Metab 295: E559-568, 2008. https://doi.org/10.1152/ajpendo.90289.2008

PINHEIRO J, BATES D, DEBROY S, SARKAR D, R CORE TEAM: NLME: Linear and nonlinear mixed effects models. R package version 3.1-137. 2018.

PLEVKOVA J, BUDAY T, KAVALCIKOVA BOGDANOVA N, KOVACIKOVA L, RUZINAK R: Role of gender in basic cough research. Respir Physiol Neurobiol 245: 53-56, 2017. https://doi.org/10.1016/j.resp.2016.12.006

R CORE TEAM: R: A language and environment for statistical computing. R Foundation for Statistical Computing, Vienna, Austria. https://www.r-project.org/, 2018.

ROORDA RJ, GERRITSEN J, VAN AALDEREN WM, SCHOUTEN JP, VELTMAN JC, WEISS ST, KNOL K: Risk factors for the persistence of respiratory symptoms in childhood asthma. Am Rev Respir Dis 148: 1490-1495, 1993. https://doi.org/10.1164/ajrccm/148.6_Pt_1.1490

SHANSKY RM: Are hormones a "female problem" for animal research? Science 364: 825-826, 2019. https://doi.org/10.1126/science.aaw7570 
SONG W-J, CHANG Y-S, FARUQI S, KIM J-Y, KANG M-G, KIM S, JO E-J, KIM M-H, PLEVKOVA J, PARK H-W, CHO S-H, MORICE AH: The global epidemiology of chronic cough in adults: a systematic review and metaanalysis. Eur Respir J 45: 1479-1481, 2015. https://doi.org/10.1183/09031936.00218714

VARECHOVA S, PLEVKOVA J, HANACEK J, TATAR M: Role of gender and pubertal stage on cough sensitivity in childhood and adolescence. J Physiol Pharmacol 59 (Suppl 6): 719-726, 2008.

VODO S, ARCELLI D, FIORENZANI P, MERIGGIOLA MC, BUTKEVICH I, DI CANIO C, MIKHAILENKO V, ALOISI AM: Gonadal ER $\alpha / \beta$, AR and TRPV1 gene expression: Modulation by pain and morphine treatment in male and female rats. Physiol Behav 110-111: 80-86, 2013. https://doi.org/10.1016/j.physbeh.2012.12.014 